\title{
Influência do processamento na qualidade proteica de novos cultivares de soja destinados à alimentação humana
}

\author{
Influence of processing on the protein quality \\ of new soybean cultivars intended \\ for human food
}

Cassiano Oliveira da SILVA ${ }^{1}$

Gláucia Ferreira ANDRADE²

Maria Inês de Souza DANTAS ${ }^{1}$

Neuza Maria Brunoro COSTA ${ }^{2}$

Maria do Carmo Gouveia PELUZIO²

Edimar Aparecida Filomeno FONTES ${ }^{1}$

Hércia Stampini Duarte MARTINO²

\section{RE S U M O}

\section{Objetivo}

Avaliar o efeito do processamento na qualidade proteica de cultivares de soja destinados à alimentação humana.

\section{Métodos}

As dietas foram preparadas a partir dos grãos dos cultivares Embrapa 48, BRS 213, BRS 155 e UFVTN 105, que receberam tratamento térmico em estufa a 130 e $150^{\circ} \mathrm{C}$, com posterior retirada ou não da casca para a produção das farinhas. Realizou-se ensaio biológico para avaliação de quociente de eficiência proteica, quociente de eficiência proteica líquida e digestibilidade verdadeira.

\section{Resultados}

Os valores de razão proteica líquida e digestibilidade das farinhas foram inferiores aos da caseína. As farinhas de soja com casca tratadas a $150^{\circ} \mathrm{C}$ apresentaram melhores índices de qualidade proteica que as farinhas sem casca tratadas a $130^{\circ} \mathrm{C}$. O quociente de eficiência proteica e o quociente de eficiência proteica líquida dos cultivares Embrapa 48 e BRS 155 foram maiores $(p<0,05)$ que os demais. O cultivar UFVTN 105 apresentou maior $(p<0,05)$ digestibilidade quando processado a $130^{\circ} \mathrm{C}$. No tratamento a $150^{\circ} \mathrm{C}$, a digestibilidade foi

1 Universidade Federal de Viçosa, Departamento de Tecnologia de Alimentos. Viçosa, MG, Brasil.

${ }^{2}$ Universidade Federal de Viçosa, Centro de Ciências Biológicas II, Departamento de Nutrição e Saúde. Av. P.H. Rolfs, s/n., 36570-000, Viçosa, MG, Brasil. Correspondência para/Correspondence to: H.S.D. MARTINO. E-mail: <hercia@ufv.br>. 
390 | C.O. SILVA et al.

inferior $(p<0,05)$ para os cultivares BRS 213 e BRS 155. Não foi observada melhoria na digestibilidade da proteína de soja quando utilizado o cultivar com baixo teor de inibidor de tripsina (BRS 155) em comparação com o cultivar convencional (Embrapa-48).

\section{Conclusão}

O tratamento térmico e a retirada ou não da casca interferiram na qualidade proteica de novos cultivares de soja destinados à alimentação humana, com melhores resultados para as farinhas com casca produzidas a partir de grãos tratados a $150^{\circ} \mathrm{C}$ por 30 minutos. O tratamento térmico favoreceu a qualidade proteica das farinhas de soja convencionais, que obtiveram valores semelhantes aos dos cultivares sem inibidor de tripsina e superiores aos dos cultivares sem lipoxigenase.

Termos de indexação: Alimentação. Digestibilidade. Processamento de alimentos. Qualidade proteica. Soja.

\section{A B S T R A C T}

\section{Objective}

The aim of this study was to evaluate the effect of processing on the protein quality of new soybean cultivars intended for human food.

\section{Methods}

The diets were prepared from the cultivars Embrapa 48, BRS 213, BRS 155 and UFVTN 105. They were heat-treated in a vacuum oven at $130^{\circ} \mathrm{C}$ and $150^{\circ} \mathrm{C}$, with subsequent removal or not of the hull for the production of soybean meals. A biological assay was done to determine the protein efficiency ratio, net protein ratio and true protein digestibility.

\section{Results}

Soybean meals had lower protein efficiency ratio, net protein ratio and digestibility than casein. Whole soybean meals treated at $150^{\circ} \mathrm{C}$ had a better protein quality index than refined soybean meals heat-treated at $130^{\circ} \mathrm{C}$. The protein efficiency ratio and net protein ratio of Embrapa 48 and BRS 155 cultivars were higher $(p<0.05)$ than the other ones. The UFVTN 105 cultivar had the highest digestibility $(p<0.05)$ when treated at $130^{\circ} \mathrm{C}$. Among the cultivars heat-treated at $150^{\circ} \mathrm{C}$, the BRS 213 and BRS 155 cultivars had the lowest digestibility $(p<0.05)$. Protein digestibility of the cultivar with low trypsin inhibitor content (BRS 155) was not better than that of the conventional Embrapa-48 cultivar.

\section{Conclusion}

Heating and removal or not of the hull affected the protein quality of the new soybean cultivars intended for human food. Whole soybean meals heat-treated at $150^{\circ} \mathrm{C}$ for 30 minutes presented the best results. Heating improved the protein quality of the conventional soybean meals. Their protein quality was similar to that of the cultivars without trypsin inhibitor and better than that of the cultivars without lipoxygenases.

Indexing terms: Feeding. Digestibility. Food handling. Protein quality. Soybean.

\section{N T R O D U ÇÃ O}

A soja é uma leguminosa de grande interesse na economia mundial e de importante significado na alimentação humana em decorrência de suas propriedades nutricionais e funcionais ${ }^{1,2}$. A produção mundial vem aumentando ${ }^{3}$, e a soja vem sendo amplamente utilizada como fonte proteica na alimentação humana e animal ${ }^{4}$, fazendo parte do grupo das cinco principais fontes proteicas alimentares 5 .
Os cultivares convencionais de soja apresentam inibidores de proteases, tais como Inibidor de Tripsina Kunitz (KTI) e Inibidor de Tripsina e Quimotripsina Bowman-Birk (BBI). Esses antinutrientes inibem as enzimas proteolíticas e, consequentemente, reduzem a digestão proteica de alimentos, proporcionando diminuição no ganho de peso e crescimento de animais ${ }^{3,4}$.

Com o melhoramento genético, novos cultivares de soja sem KTI, lectinas e lipoxigenases vêm sendo desenvolvidos com o intuito de melho- 
rar a qualidade proteica e o sabor, tornando-os mais apropriados para a alimentação huma$n a^{4,6-8}$.

O processamento da soja é um determinante da sua qualidade proteica. Estudo realizado por Silva et al. ${ }^{9}$ mostrou que a casca pode interferir na qualidade proteica da soja por ser fonte de fibra alimentar e fatores antinutricionais, justificando o uso de grãos de soja sem $\operatorname{casca}^{6,10}$. O tratamento térmico também é um determinante da qualidade proteica, pois pode inibir fatores antinutricionais de cultivar de soja convencional ${ }^{8}$ e alterar a estrutura das proteínas, elevando a digestibilidade ${ }^{11}$.

Torna-se importante pesquisar o efeito do tratamento térmico em grãos de soja de cultivares não convencionais e convencionais, desenvolvidos para a alimentação humana, processados em farinhas com e sem casca. A preservação das características nutricionais e a inativação de fatores antinutricionais podem otimizar o consumo de soja na alimentação humana.

O objetivo do presente estudo foi avaliar o efeito do processamento na qualidade proteica de cultivares de soja destinados à alimentação humana.

\section{M É T O D O S}

Foram utilizados quatro cultivares de soja destinados à alimentação humana. Os cultivares Embrapa 48, BRS 155 e BRS 213 foram fornecidos pela Embrapa Soja de Londrina (PR). O cultivar Embrapa 48 é convencional e tem sido preferido pela indústria brasileira de extrato de soja. O cultivar BRS 155 apresenta teor reduzido de inibidor de tripsina e o cultivar BRS 213 é isento de lipoxigenases. O cultivar UFVTN 105, sem lipoxigenase, foi fornecido pelo Instituto de Biotecnologia Aplicada à Agropecuária (BIOAGRO) da Universidade Federal de Viçosa.

\section{Produção da farinha de soja}

Em um estudo prévio em laboratório (dados não publicados), os cultivares de soja Embrapa
48, BRS 213, BRS 155 e UFVTN 105, tratados termicamente a 130 e $150^{\circ} \mathrm{C}$ por 30 minutos em estufa com circulação de ar, apresentaram alta solubilidade proteica e o tratamento a $150^{\circ} \mathrm{C}$ foi eficiente em inativar urease. Diante desse resultado, os grãos de soja foram submetidos à temperatura de 130 e $150^{\circ} \mathrm{C}$ por 30 minutos em estufa com circulação de ar (marca Marconi), resfriados e moídos com casca em miniprocessador (marca Arno), e passados em peneira de 40 mesh $(0,42 \mathrm{~mm})$, produzindo farinha de soja com casca, ou seja, integral. Para a produção da farinha de soja refinada, sem casca, os grãos após o tratamento térmico foram quebrados no miniprocessador para facilitar a remoção da casca. Os grãos em pedaços, sem casca, foram moídos e peneirados em peneira de 40 mesh $(0,42 \mathrm{~mm})$. Ao final processaram-se 16 tipos de farinhas - obtidas de quatro cultivares de soja, com e sem casca, tratados a 130 e $150^{\circ} \mathrm{C}$ - que foram armazenados em sacos plásticos, codificados e mantidos sob refrigeração.

\section{Dietas experimentais}

A composição das dietas experimentais foi baseada na dieta AIN-93G ${ }^{12}$, modificada de modo a fornecer 9,5\% de proteína (Tabela 1). O teor de proteína das farinhas e das dietas foi determinado em triplicata, pelo método semimicro Kjeldahl'13, multiplicando-se o teor de nitrogênio pelo fator de conversão 6,25.

O grupo padrão recebeu Dieta de Caseína (CAS) como fonte proteica, outro grupo recebeu dieta Livre de Nitrogênio (LN) e os demais grupos experimentais foram alimentados com dietas à base de farinhas de soja. Os grupos receberam as seguintes denominações: D1: Embrapa $48,130^{\circ} \mathrm{C}$ com casca; D2: Embrapa $48,150^{\circ} \mathrm{C}$ com casca; D3: Embrapa 48, $130^{\circ} \mathrm{C}$ sem casca; D4: Embrapa $48,150^{\circ} \mathrm{C}$ sem casca; D5: UFVTN $105,130^{\circ} \mathrm{C}$ com casca; D6: UFVTN $105,150^{\circ} \mathrm{C}$ com casca; D7: UFVTN $105,130^{\circ} \mathrm{C}$ sem casca; D8: UFVTN 105 , $150^{\circ} \mathrm{C}$ sem casca; D9: BRS $213,130^{\circ} \mathrm{C}$ com casca; D10: BRS $213,150^{\circ} \mathrm{C}$ com casca; D11: BRS 213, 
392 | C.O. SILVA et al.

$130^{\circ} \mathrm{C}$ sem casca; D12: BRS $213,150^{\circ} \mathrm{C}$ sem casca; D13: BRS $155,130^{\circ} \mathrm{C}$ com casca; D14: BRS $155,150^{\circ} \mathrm{C}$ com casca; D15: BRS $155,130^{\circ} \mathrm{C}$ sem casca; D16: BRS $155,150^{\circ} \mathrm{C}$ sem casca.

Devido ao elevado teor de lipídeos da soja, não foi acrescentado óleo nas dietas experimentais com farinha de soja. Nas dietas com farinha de soja com casca também não foi acrescentada celulose, como fonte de fibra alimentar (Tabela 1).

\section{Desenho experimental}

A avaliação da qualidade proteica das dietas experimentais foi conduzida por meio de ensaio biológico, durante 14 dias, utilizando-se 96 ratos machos (Rattus norvegicus, variedade albinus, classe Rodentia), da linhagem Wistar, recém-desmamados, com 23 dias de idade, com peso médio de $56 \mathrm{~g}$, obtidos do Biotério do Centro de Ciências Biológicas e da Saúde da Universidade Federal de Viçosa, Viçosa (MG).
Os animais foram divididos em grupos de seis, de forma sistemática, de modo que a diferença entre as médias dos pesos não excedesse 2,2g, atendendo a recomendação da Association of Official Analytical Chemists (AOAC) ${ }^{13}$. Foram mantidos em gaiolas de aço inoxidável individuais, em ambiente com temperatura controlada de $22^{\circ} \mathrm{C}$, desvio-padrão $=3^{\circ} \mathrm{C}$, com ciclo de luz de 12 horas, recebendo água e alimento ad libitum. $\mathrm{O}$ peso corporal e o consumo alimentar dos animais foram registrados semanalmente durante o período experimental de 14 dias.

Para avaliação da digestibilidade proteica, no $8^{\circ}$ e no $11^{\circ}$ dias do experimento, os animais receberam dietas marcadas com $200 \mathrm{mg}$ de índigo carmim $/ 100 \mathrm{~g}$ de dieta. As fezes marcadas foram coletadas no $9^{\circ}$ dia, bem como a totalidade das fezes no $10^{\circ}$ e $11^{\circ}$ dias e as fezes não marcadas no $12^{\circ} \mathrm{dia}$. As fezes coletadas nesse período foram acondicionadas em recipientes individuais e mantidas sob refrigeração. Posteriormente, as fezes foram secas em estufa com circulação de ar (marca MARCONI) a $105^{\circ} \mathrm{C}$, durante 24 horas.

Tabela 1. Composição das dietas experimentais e percentual de proteínas (g/100g). Viçosa (MG), 2007.

\begin{tabular}{lcccccccccccc}
\hline Dietas & CS & FS & AD & SC & OS & FB & MM & MV & LC & BC & AM & \% proteínas \\
\hline LN & - & - & 13,2 & 10 & 7 & 5 & 3,5 & 1 & 0,3 & 0,25 & 59,6 & 0,5 \\
CAS & 12 & - & 13,2 & 10 & 7 & 5 & 3,5 & 1 & 0,3 & 0,25 & 47,7 & 9,2 \\
D1 & - & 25,0 & 13,2 & 10 & - & - & 3,5 & 1 & 0,3 & 0,25 & 46,7 & 9,5 \\
D2 & - & 24,5 & 13,2 & 10 & - & - & 3,5 & 1 & 0,3 & 0,25 & 46,3 & 9,8 \\
D3 & - & 24,2 & 13,2 & 10 & - & 5 & 3,5 & 1 & 0,3 & 0,25 & 42,5 \\
D4 & - & 24,0 & 13,2 & 10 & - & 5 & 3,5 & 1 & 0,3 & 0,25 & 42,8 & 9,5 \\
D5 & & 22,1 & 13,2 & 10 & - & - & 3,5 & 1 & 0,3 & 0,25 & 49,7 \\
D6 & - & 22,3 & 13,2 & 10 & - & - & 3,5 & 1 & 0,3 & 0,25 & 49,5 \\
D7 & - & 20,8 & 13,2 & 10 & - & 5 & 3,5 & 1 & 0,3 & 0,25 & 46,0 & 9,4 \\
D8 & - & 22,0 & 13,2 & 10 & - & 5 & 3,5 & 1 & 0,3 & 0,25 & 44,8 \\
D9 & - & 24,5 & 13,2 & 10 & - & - & 3,5 & 1 & 0,3 & 0,25 & 47,3 \\
D10 & - & 23,8 & 13,2 & 10 & - & - & 3,5 & 1 & 0,3 & 0,25 & 47,9 \\
D11 & - & 23,4 & 13,2 & 10 & - & 5 & 3,5 & 1 & 0,3 & 0,25 & 43,4 \\
D12 & - & 23,7 & 13,2 & 10 & - & 5 & 3,5 & 1 & 0,3 & 0,25 & 43,0 \\
D13 & - & 23,7 & 13,2 & 10 & - & - & 3,5 & 1 & 0,3 & 0,25 & 48,1 \\
D14 & - & 22,8 & 13,2 & 10 & - & - & 3,5 & 1 & 0,3 & 0,25 & 9,7 \\
D15 & - & 23,0 & 13,2 & 10 & - & 5 & 3,5 & 1 & 0,3 & 0,25 & 43,8 \\
D16 & - & 23,0 & 13,2 & 10 & - & 5 & 3,5 & 1 & 0,3 & 0,25 & 43,8 \\
\hline
\end{tabular}

Dietas - CAS: caseína; LN: dieta livre de nitrogênio; D1: Embrapa 48, $130^{\circ} \mathrm{C}$ com casca; D2: Embrapa $48,150^{\circ} \mathrm{C}$ com casca; D3: Embrapa 48 $130^{\circ} \mathrm{C}$ sem casca; D4: Embrapa $48,150^{\circ} \mathrm{C}$ sem casca; D5: UFVTN 105, $130^{\circ} \mathrm{C}$ com casca; D6: UFVTN 105, $150^{\circ} \mathrm{C}$ com casca; D7: UFVTN 105 , $130^{\circ} \mathrm{C}$ sem casca; D8: UFVTN 105, $150^{\circ} \mathrm{C}$ sem casca; D9: BRS 213, $130^{\circ} \mathrm{C}$ com casca; D10: BRS $213,150^{\circ} \mathrm{C}$ com casca; D11: BRS $213,130^{\circ} \mathrm{C}$ sem casca; D12: BRS $213,150^{\circ} \mathrm{C}$ sem casca; D13: BRS $155,130^{\circ} \mathrm{C}$ com casca; D14: BRS $155,150^{\circ} \mathrm{C}$ com casca; D15: BRS $155,130^{\circ} \mathrm{C}$ sem $\mathrm{Casca}$; 16 : BRS $155,150^{\circ} \mathrm{C}$ sem casca.

Ingredientes - CS: caseína; FS: farinha de soja; AD: amido dextrinizado; SC: sacarose; OS: óleo de soja; FB: fibra (celulose); MM: mistura mineral; MV: mistura vitamínica; LC: L-cistina; BC: bitartarato de colina; AM: amido de milho. 
Em seguida, foram resfriadas, pesadas e moídas em miniprocessador da marca Arno para determinação em triplicata do teor de nitrogênio pelo método semimicro Kjeldahl13. ${ }^{13}$ O teor de nitrogênio das fezes dos grupos experimentais foi utilizado para o cálculo da digestibilidade verdadeira ${ }^{14}$.

Os animais foram submetidos à eutanásia, ao término do experimento, por asfixia em meio contendo $\mathrm{CO}_{2}$.

O Quociente de Eficiência Proteica (PER) foi determinado considerando-se o ganho de peso do grupo-teste em relação ao consumo de proteína do grupo-teste, segundo o método de Hegsted modificado para 14 dias $^{15}$. A Razão Proteica Líquida (NPR) foi determinada no $14^{\circ}$ dia do experimento, considerando o ganho de peso do grupo-teste mais a perda de peso do grupo livre de nitrogênio, em relação ao consumo de proteína do grupo-teste, segundo o método de Bender \& Doell ${ }^{14}$.

Os procedimentos adotados no ensaio biológico atenderam a prática didático-científica da vivissecção de animais, sendo aprovado pelo Comitê de Ética em Experimentação animal (CETEA) da Universidade Federal de Minas Gerais (protocolo $n^{\circ}$ 36/2007).
Para análise do PER, NPR e digestibilidade, os tratamentos experimentais foram dispostos em um delineamento inteiramente casualizado com seis repetições, utilizando um esquema fatorial $4 \times 2 \times 2$, sendo quatro cultivares, dois tratamentos térmicos e duas farinhas de soja, com e sem casca.

Os dados foram interpretados por meio de análise de variância utilizando teste $\mathrm{F}$ e as médias comparadas utilizando o teste de Duncan ao nível de $5 \%$ de probabilidade. As análises estatísticas foram realizadas no programa Statistical Analysis Systems (SAS), versão 9.1, licenciado para a Universidade Federal de Viçosa ${ }^{16}$.

\section{RE S U LT A D OS}

Os animais que receberam farinhas de soja de diferentes cultivares apresentaram índices de qualidade proteica, como PER, NPR e digestibilidade menores que ao da caseína. O percentual de adequação médio relativo à caseína, avaliado pelo R-PER, R-NPR e R-DV, variou de 37,3 a 68,5\%, 51,8 a $72,3 \%$ e 75,5 a $87,8 \%$, respectivamente (Tabela 2).

Tabela 2. Valores médios de PER, NPR e digestibilidade verdadeira dos grupos experimentais recebendo farinhas de diferentes cultivares de soja. Viçosa (MG), 2007.

\begin{tabular}{|c|c|c|c|c|c|c|c|c|c|}
\hline \multirow{2}{*}{ Tratamentos } & \multicolumn{2}{|c|}{ PER } & \multirow{2}{*}{$\begin{array}{c}\text { R-PER } \\
(\%)\end{array}$} & \multicolumn{2}{|c|}{ NPR } & \multirow{2}{*}{$\begin{array}{c}\text { R-NPR } \\
(\%)\end{array}$} & \multicolumn{2}{|c|}{ DV } & \multirow{2}{*}{$\begin{array}{l}\text { R-DV } \\
(\%)\end{array}$} \\
\hline & M & DP & & M & DP & & M & DP & \\
\hline Caseína & 3,75 & 0,39 & 100,0 & 4,34 & 0,37 & 100,0 & 95,52 & 2,60 & 100,0 \\
\hline Embrapa $48130^{\circ} \mathrm{C}$ com casca & 2,08 & 0,60 & 55,5 & 2,77 & 0,49 & 63,8 & 76,13 & 5,31 & 79,7 \\
\hline Embrapa $48150^{\circ} \mathrm{C}$ com casca & 2,40 & 0,26 & 64,0 & 3,14 & 0,33 & 72,3 & 83,83 & 5,21 & 87,8 \\
\hline Embrapa $48130^{\circ} \mathrm{C}$ sem casca & 1,76 & 0,25 & 46,9 & 2,53 & 0,18 & 58,3 & 72,59 & 5,42 & 76,0 \\
\hline Embrapa $48150^{\circ} \mathrm{C}$ sem casca & 2,57 & 0,22 & 68,5 & 3,21 & 0,24 & 74,0 & 79,68 & 2,81 & 83,4 \\
\hline UFVTN $105130^{\circ} \mathrm{C}$ com casca & 1,83 & 0,41 & 48,8 & 2,62 & 0,36 & 60,4 & 80,56 & 4,68 & 84,3 \\
\hline UFVTN $105150^{\circ} \mathrm{C}$ com casca & 2,25 & 0,31 & 60,0 & 2,97 & 0,30 & 68,4 & 82,40 & 3,76 & 86,3 \\
\hline UFVTN $105130^{\circ} \mathrm{C}$ sem casca & 1,58 & 0,41 & 42,1 & 2,32 & 0,41 & 53,5 & 79,11 & 4,88 & 82,8 \\
\hline UFVTN $105150^{\circ} \mathrm{C}$ sem casca & 1,99 & 0,21 & 53,1 & 2,77 & 0,21 & 63,8 & 78,80 & 4,63 & 82,5 \\
\hline BRS $213130^{\circ} \mathrm{C}$ com casca & 1,58 & 0,42 & 42,1 & 2,42 & 0,37 & 55,8 & 78,36 & 2,40 & 82,1 \\
\hline BRS $213150^{\circ} \mathrm{C}$ com casca & 2,11 & 0,10 & 56,3 & 2,89 & 0,12 & 66,6 & 74,96 & 3,91 & 78,5 \\
\hline BRS $213130^{\circ} \mathrm{C}$ sem casca & 1,40 & 0,56 & 37,3 & 2,25 & 0,42 & 51,8 & 72,11 & 2,77 & 75,5 \\
\hline BRS $213150^{\circ} \mathrm{C}$ sem casca & 1,80 & 0,46 & 48,0 & 2,55 & 0,48 & 58,7 & 78,30 & 3,16 & 82,0 \\
\hline BRS $155130^{\circ} \mathrm{C}$ com casca & 1,66 & 0,54 & 44,3 & 2,52 & 0,49 & 58,1 & 73,76 & 5,33 & 77,2 \\
\hline BRS $155150^{\circ} \mathrm{C}$ com casca & 2,56 & 0,32 & 68,3 & 3,26 & 0,30 & 75,1 & 78,57 & 0,77 & 82,3 \\
\hline BRS $155130^{\circ} \mathrm{C}$ sem casca & 1,68 & 0,39 & 44,8 & 2,37 & 0,31 & 54,6 & 71,45 & 9,25 & 74,8 \\
\hline BRS $155150^{\circ} \mathrm{C}$ sem casca & 2,41 & 0,17 & 64,3 & 3,09 & 0,23 & 71,2 & 78,30 & 4,05 & 82,0 \\
\hline
\end{tabular}

M: média; DP: desvio-padrão. DV: digestibilidade verdadeira; PER: quoeficiente de eficiência proteica; NPR: razão proteica líquida. 
Não houve interação significativa entre cultivares de soja, tratamento térmico aplicado aos grãos e farinha de soja com ou sem casca $(p>0,05)$, uma vez que esses fatores atuam de forma independente sobre o PER e o NPR. Houve diferença $(p<0,05)$ de cada fator em estudo sobre os valores de PER, NPR e digestibilidade.

A farinha de soja do cultivar Embrapa 48 não apresentou diferença em relação à BRS 155 $(p>0,05)$, entretanto foi superior $(p<0,05)$ aos cultivares UFVTN 105 e BRS 213 (Tabela 3).

Tabela 3. Valores médios de PER e NPR de cultivares de soja cujos grãos foram submetidos a diferentes tratamentos térmicos para obtenção de farinha de soja com e sem casca. Viçosa (MG), 2007.

\begin{tabular}{|c|c|c|c|c|}
\hline \multirow{2}{*}{ Cultivares de soja } & \multicolumn{2}{|c|}{ PER } & \multicolumn{2}{|c|}{ NPR } \\
\hline & M & DP & M & DP \\
\hline Embrapa 48 & 2,18 & $0,47^{\mathrm{a}}$ & 2,91 & $0,42^{\mathrm{a}}$ \\
\hline BRS 155 & 2,08 & $0,55^{\mathrm{ab}}$ & 2,81 & $0,50^{\text {ab }}$ \\
\hline UFVTN 105 & 1,91 & $0,41^{b c}$ & 2,67 & $0,39^{b c}$ \\
\hline BRS 213 & 1,72 & $0,48^{c}$ & 2,53 & $0,42^{c}$ \\
\hline Tratamento térmico & \multicolumn{2}{|c|}{ PER } & \multicolumn{2}{|c|}{ NPR } \\
\hline $150^{\circ} \mathrm{C} / 30$ minutos & 2,26 & $0,36^{\mathrm{a}}$ & 2,98 & $0,35^{\mathrm{a}}$ \\
\hline $130^{\circ} \mathrm{C} / 30$ minutos & 1,69 & $0,46^{\mathbf{b}}$ & 2,47 & $0,39^{\mathbf{b}}$ \\
\hline Farinha de soja & \multicolumn{2}{|c|}{ PER } & \multicolumn{2}{|c|}{ NPR } \\
\hline Com casca & 2,05 & $0,49^{a}$ & 2,82 & $0,44^{\mathrm{a}}$ \\
\hline Sem casca & 1,89 & $0,50^{b}$ & 2,64 & $0,45^{\mathbf{b}}$ \\
\hline
\end{tabular}

M: média; DP: desvio-padrão; PER: quoeficiente de eficiência protéica; NPR: razão proteica líquida.

Médias seguidas pela mesma letra, na coluna, não diferem entre si pelo Teste de Duncan ao nível de $5 \%$ de probabilidade.

Tabela 4. Valores médios da digestibilidade de farinha de soja obtida de diferentes cultivares cujos grãos foram submetidos a diferentes tratamentos térmicos. Viçosa (MG), 2007.

\begin{tabular}{lccccc}
\hline \multirow{2}{*}{$\begin{array}{l}\text { Farinhas de soja } \\
\text { processadas }\end{array}$} & \multicolumn{4}{c}{ Tratamento térmico } \\
\cline { 2 - 3 } \cline { 5 - 6 } & \multicolumn{1}{c}{$130^{\circ} \mathrm{C} / 30$ minutos } & & $150^{\circ} \mathrm{C} / 30$ minutos \\
\cline { 2 - 3 } \cline { 5 - 6 } & $\mathrm{M}$ & $\mathrm{DP}$ & & $\mathrm{M}$ & $\mathrm{DP}$ \\
\hline UFVTN 105 & 79,83 & $4,62^{\mathrm{aB}}$ & & 80,60 & $4,44^{\mathrm{aA}}$ \\
Embrapa 48 & 74,36 & $5,44^{\mathrm{bB}}$ & & 81,75 & $4,54^{\mathrm{aA}}$ \\
BRS 155 & 72,60 & $7,29^{\mathrm{BB}}$ & & 78,43 & $2,78^{\mathrm{abA}}$ \\
BRS 213 & 75,23 & $4,09^{\mathrm{bA}}$ & & 76,83 & $3,81^{\mathrm{bA}}$ \\
\hline
\end{tabular}

Médias seguidas pela mesma letra minúscula na coluna não diferem entre si pelo teste de Duncan ao nível de $5 \%$ de probabilidade. Médias seguidas pela mesma letra maiúscula na linha não diferem entre si pelo teste de Duncan ao nível de 5\% de probabilidade. M: média; DP: desvio-padrão.
As farinhas submetidas ao tratamento térmico de $150^{\circ} \mathrm{C} / 30$ minutos apresentaram valores de PER e NPR superiores $(p<0,05)$ àqueles apresentados pelas processadas a $130^{\circ} \mathrm{C} / 30$ minutos. Já nas farinhas processadas com casca, o PER e NPR foram superiores $(p<0,05)$ aos das processadas sem casca.

Para a digestibilidade houve efeito de interação das variáveis cultivar e temperatura. O cultivar UFVTN 105 apresentou digestibilidade superior $(p<0,05)$ aos demais quando o grão foi submetido à temperatura de $130^{\circ} \mathrm{C} / 30$ minutos. Quando os grãos foram tratados a $150^{\circ} \mathrm{C} / 30$ minutos, não houve diferença $(p>0,05)$ entre os cultivares UFVTN 105, Embrapa-48 e BRS 155, entretanto estes apresentaram digestibilidade superior ao BRS 213. Nos cultivares Embrapa-48 e BRS 155, a digestibilidade foi maior $(p<0,05)$ nas farinhas obtidas de grãos tratados a $150^{\circ} \mathrm{C} / 30$ minutos (Tabela 4).

Assim como o verificado para PER e NPR, os cultivares com casca apresentaram valores de digestibilidade de $78,57 \%$, superiores $(p<0,05)$ aos cultivares sem casca - 76,29\%.

\section{I S C U S S Ã O}

A superioridade da caseína em relação às farinhas de soja era esperada, tendo em vista que a proteína de soja, reconhecidamente, é deficiente em aminoácidos sulfurados, como metionina e cisteína, o que limita sua utilização para síntese proteica $^{17,18}$.

Os valores de PER e NPR foram superiores aos encontrados por Monteiro et al. ${ }^{4}$, que utilizaram grãos de soja sem casca de características semelhantes às variedades utilizadas no presente estudo, tratados em estufa a $89^{\circ} \mathrm{C} / 5$ minutos. Esses autores encontraram valores de PER, respectivamente, de 1,25 e 1,16 para farinha de soja sem lipoxigenase, sem e com inibidor de tripsina Kunitz e os valores de NPR foram respectivamente 2,34 e 2,27 . 
Mendes et al. ${ }^{19}$ obtiveram valores de PER e NPR respectivamente iguais a 1,83 e 3,03 para farinhas de soja integral sem lipoxigenase tratada em autoclave a $120^{\circ} \mathrm{C}$ por 12 minutos.

A adequada seleção da temperatura para o tratamento térmico dos grãos de soja possibilitou melhoria na qualidade da proteína, auxiliando no maior crescimento e manutenção de peso dos ratos, visto que o tratamento térmico das farinhas a $150^{\circ} \mathrm{C}$ apresentou PER e NPR superiores $(p<0,05)$ ao das farinhas tratadas a $130^{\circ} \mathrm{C}$.

O PER e o NPR da farinha de soja produzida a partir da cultivar BRS-155, com teor reduzido de inibidor de tripsina, foram ligeiramente superiores aos observados por Miura et al. ${ }^{7}$, que obteve PER e NPR iguais a 1,93 e 2,37, respectivamente, em ratos recebendo farinha de soja desengordurada com casca com baixa atividades residuais de inibidores de tripsina.

De acordo com os resultados apresentados, observa-se que os valores de PER relativo foram inferiores aos valores de NPR relativo (Tabela 2), o que demonstra que a proteína de soja presta-se melhor para a manutenção do peso dos ratos que para promover crescimento.

A medida da digestibilidade indica a eficiência com a qual as proteínas são hidrolisadas pelas enzimas digestivas e absorvidas pelo organismo, constituindo o primeiro fator que afeta a eficiência da utilização proteica da dieta. A digestibilidade das farinhas foi inferior $(p<0,05)$ à da caseína e também aos valores encontrados por Monteiro et al. ${ }^{4}$, que obtiveram $87,9 \%$ e $91,5 \%$ de digestibilidade proteica em farinha de soja sem lipoxigenase e sem KTI, respectivamente. Machado et al. ${ }^{8}$ obtiveram valores de digestibilidade próximos a $90 \%$ após 25 minutos de aplicação de calor úmido a $121^{\circ} \mathrm{C}$ tanto em soja convencional quanto em cultivar sem KTI e lectina.

O cultivar BRS-155 com teor reduzido de inibidor de tripsina Kunitz teve um resultado de NPR, PER e digestibilidade semelhante ao cultivar convencional, Embrapa 48. Provavelmente o trata- mento térmico tenha favorecido a inativação dos fatores antinutricionais presentes no cultivar Embrapa 48, corroborando os achados de Machado et al. ${ }^{8}$, em que a maior inativação do inibidor de tripsina aconteceu em cultivares convencional e sem KTI e lectina, tratados termicamente em autoclave, $121^{\circ} \mathrm{C}$ por 15 minutos do que em tempos menores.

Herkelman et al. ${ }^{17}$ estudaram, em suínos, o efeito do tratamento térmico sobre a digestibilidade aparente da proteína da soja de cultivar com teor normal e reduzido de inibidor de tripsina Kunitz. Os animais alimentados com dietas contendo soja convencional apresentaram desempenho inferior aos de animais que receberam dietas à base de soja com baixo teor de inibidor de tripsina Kunitz. Porém, quando os cultivares foram tratados termicamente em autoclave, $110^{\circ} \mathrm{C} / 20 \mathrm{~min}$, houve um aumento do valor nutricional dos cultivares convencional e com baixo teor de inibidor de tripsina.

A casca da soja é fonte de fibra alimentar e tem fatores antinutricionais, podendo interferir na qualidade proteica das farinhas ${ }^{9}$. Entretanto, a farinha de soja com casca apresentou melhor qualidade proteica que a sem casca. Tal fato pode ter ocorrido pelo fato de o tratamento térmico ter reduzido o teor de fatores antinutricionais nas farinhas. Silva et al. ${ }^{9}$, comparando o resíduo da extração de óleo de soja com o grão integral processado em panela de pressão por 20 minutos, não observaram diferenças significativas entre esses tratamentos com relação aos índices biológicos NPR e Utilização Proteica Líquida (NPU).

\section{CONCLUSÃO}

Os efeitos dos processamentos, tratamento térmico e retirada ou não da casca interferiram na qualidade proteica de novos cultivares de soja destinados à alimentação humana, ocorrendo melhora na qualidade proteica farinhas com casca produzidas a partir de grãos tratados a $150^{\circ} \mathrm{C}$ por 30 minutos. 
396 | C.O. SILVA et al.

Não foi observada melhora na digestibilidade da proteína de soja quando utilizada variedade com baixo teor de inibidor de tripsina Kunitz em comparação com o cultivar convencional, indicando que o tratamento térmico foi suficiente para reduzir o teor de fatores antinutricionais e melhorar a qualidade da proteína da soja do cultivar convencional.

O tratamento térmico adequado favoreceu a utilização de farinhas de soja convencionais, tornando-as de valor proteico semelhante ao cultivar sem inibidor de tripsina e superior aos cultivares sem lipoxigenase. São necessários novos estudos para quantificar o teor dos fatores antinutricionais nos cultivares estudados.

\section{A GRADECIMENTOS}

Ao Conselho Nacional de Desenvolvimento Científico e Tecnológico pela concessão da bolsa de iniciação científica (PIBIC/CNPq/UFV). Ao Instituto de Biotecnologia Aplicada à Agropecuária e à dra. Mercedes C. Carrão-Panizzi da Empresa Brasileira de Pesquisa Agropecuária Soja de Londrina (PR) pela disponibilização dos cultivares de soja.

\section{COLABORADORES}

C.O. SILVA, G.F. ANDRADE e H.S.D. MARTINO contribuíram para o planejamento, a execução, as análises estatísticas e para a elaboração da versão escrita de todo o artigo. M.I.S. DANTAS e N.M.B. COSTA contribuíram para o planejamento do experimento e da discussão dos resultados do artigo científico. M.C.G. PELUZIO contribuiu para a execução do trabalho e discussão dos resultados do artigo. E.A.F. FONTES contribuiu para as análises estatísticas e discussão do artigo.

\section{REFERÊ NCIAS}

1. Magee PJ, Rowland IR. Phyto-oestrogens, their mechanism of action: current evidence for a role in breast and prostate cancer. Br J Nutr. 2004; 91 : 513-31. doi: 10.1079/BJN20031075.
2. Zhang X, Shu XO, Li H, Yang G, Li Q, Gao Y-T, et al. Prospective cohort study of soy food consumption and risk of bone fracture among postmenopausal women. Arch Intern Med. 2005;165:1890-5.

3. Miura EMY, Silva RSSF, Mizubuti IY, Ida El. Cinética de inativação de inibidores de tripsina e de insolubilização de proteínas de diferentes cultivares de soja. Rev Bras Zootec. 2005; 3:1659-65. doi: 10.15 90/S1516-35982005000500028.

4. Monteiro MRP, Costa NMB, Oliveira MGA, Pires $C V$, Moreira MA. Qualidade proteica de linhagens de soja com ausência do Inibidor de Tripsina Kunitz e das isoenzimas Lipoxigenases. Rev Nutr. 2004; 17(2):195-205. doi: 10.1590/S1415-52732004 000200006.

5. Mendes WS, Silva IJ, Fontes DO, Rodriguez NM, Marinho PC, Silva FO, et al. Composição química e valor nutritivo da soja crua e submetida a diferentes processamentos térmicos para suínos em crescimento. Arq Bras Med Vet Zootec. 2004; 56(2):207-13.

6. Carrão-Panizzi MC. Melhoramento genético da soja para a obtenção de cultivares mais adequados ao consumo humano. Rev Bras Nutr Clín. 2000; 15(2):330-40.

7. Miura EMY, Binotti MAR, Camargo DS, Mizubuti IY, Ida El. Avaliação biológica de soja com baixas atividades de inibidores de tripsina e ausência do inibidor Kunitz. Arch Latinoam Nutr. 2001; 51(2): 1-8.

8. Machado FPP, Queiróz JH, Oliveira MGA, Piovesan ND, Peluzio MCG, Costa NMB, et al. Effects of heating on protein quality of soybean flour devoid of Kunitz inhibitor and lectin. Food Chem. 2008; 107:649-55. doi:10.1016/j.physletb.2003.10.0 71.

9. Silva MS, Naves MMV, Oliveira RB, Leite OSM. Composição química e valor proteico do resíduo de soja em relação ao grão de soja. Cien Tecn Aliment. 2006; 26(3):571-6. doi: 10.1590/S0101-2 0612006000300014.

10. Pires CV, Oliveira MGA, Rosa JC, Costa NMB. Qualidade e escore químico de aminoácidos de diferentes fontes proteicas. Ciênc Tecn Aliment. 2006; 26(1):179-187. doi: 10.1590/S0101-20612 006000100029.

11. Carvalho MRB, Kirschnik PG, Paiva KC, Aiura FS. Evaluation of trypsin inhibitors activity after enzymatic digestion in heat-treated soybean. Rev Nutr. 2002; 15(3):267-72. doi: 10.1590/S1415-52 732002000300002 .

12. Reeves PG, Nielsen FH, Fahey GC. AIN-93 purified diets for laboratory rodents: final report of the American Institute of Nutrition ad hoc writing 
committee on the reformulation of the AIN-76A rodent diet. J Nutr. 1993; 123(11):1939-51.

13. Association of Official Analytical Chemists. Official Methods of Analysis of AOAC International. 17th ed. Maryland: AOAC; 1997.

14. Bender $A E$, Doell $B H$. Note on the determination of net protein utilization by carcass analysis. $\mathrm{Br} \mathrm{J}$ Nutr. 1957; 11:138-43. doi:10.1079/BJN19570028.

15. Hegsted DM. Protein quality and its determination. In: Whitaker JR, Tannenbauum SR, editors. Food proteins. Westport: AVI Publishing; 1977. p.347-62.

16. SAS System for Windows. Version 9.00. Cary (NC): SAS Institute; 2002.

17. Herkelman KL, Cromwell GL, Pfeiffer TW, Knabe DA. Apparent digestibility of amino acids in raw and heated conventional and low trypsin inhibitor soybeans for pigs. J Anim Sci. 1992; 70(3): 818-26.

18. Friedman M, Brandon DL. Nutritional and health benefits of soy proteins. J Agric Food Chem. 2001; 49(3):1069-86. doi: 10.1021/jf0009246.

19. Mendes FQ, Oliveira MGA, Cardoso LR, Costa NMB, Sant'ana RCO. Digestibilidade proteica e caracterização bromatológica de linhagens de soja com ausência ou presença de inibidor de tripsina Kunitz e das isozimas lipoxigenases. Biosc J. 2007; 23(1):14-21.

Recebido em: 30/7/2008

Versão final reapresentada em: 7/10/2009

Aprovado em: 18/3/2010 